4 Pickering G. Reversibility of malignant hypertension: follow-up of three cases. Lancet 1971 ; : $: 413-8$.

${ }^{5}$ Epstein M, Berk DP, Hollenberg NK, et al. Renal failure in the patient with cirrhosis. The role of active vasoconstriction. Am F Med 1970;49: 175-85.

(Accepted 18 fanuary 1984)

Service de Néphrologie, Hôpital Tenon, 75020 Paris, France

A MEYRIER, MD, associate professor of nephrology

J P LAABAN, MD, fellow in nephrology

A KANFER, MD, consultant in nephrology

Correspondence to: Professor Ag Alain Meyrier, Service de Néphrologie, Hôpital Avicenne, 93000 Bobigny, France.

\section{Intravenous sedation for upper gastrointestinal endoscopy: diazepam versus midazolam}

Intravenous diazepam (Valium) has a long half life ( $>20$ hours) and active metabolites and, possibly due to its vehicle, may damage veins; in contrast, midazolam hydrochloride (Hypnovel), a new water soluble imidazobenzodiazepine, has an elimination half life of about two hours. We compared these two drugs as sedatives for elective upper gastrointestinal endoscopy.

\section{Patients, methods, and results}

A total of 149 patients aged 21-76 years were allocated at random to receive intravenous midazolam or diazepam. Treatments were allocated by a prerandomised balanced code not known to either patient or assessor. Because of differences in colour and viscosity of the two solutions they were administered by a physician not participating in endoscopy or assessments.

After sucking a benzocaine tablet the patient received intravenous hyoscine butylbromide $20 \mathrm{mg}$ (Buscopan) followed by diazepam $10 \mathrm{mg}$ or midazolam $7.5 \mathrm{mg}$ as a bolus (with smaller doses for elderly patients) into a large vein in the antecubital fossa. Further increments were given rapidly until the physician judged sedation to be adequate; maximal sedation was not awaited.

Recovery from sedation was monitored subjectively by questionnaire and objectively by a paper and pencil task (Trieger test), ${ }^{1}$ which assesses psychomotor function, and by critical flicker fusion, ${ }^{2}$ which reflects central integration. The endoscopists rated as "excellent," "good," "fair," or "poor" the following: patient cooperation; overall tolerance of the procedure; ease of examination; muscle relaxation; and control of gag reflex, laryngospasm and retching, vomiting, and salivation. Before discharge at two hours and again at 24 hours the patients completed a questionnaire on recall and pleasantness or unpleasantness of the procedure. The veins were checked again after one week.

Frequency tables were tested using either Fisher's exact or the $\chi^{2}$ (with Yates's correction) two tailed test.

The mean dose of midazolam was $10.3 \mathrm{mg}$ (range $5-15 \mathrm{mg}$ ) and of diazepam $12.5 \mathrm{mg}$ (range $10-20 \mathrm{mg}$ ). The speed of injection and rapidity of onset of sedation were similar in both groups; the mean times from injection to the start of endoscopy were 1.9 (SD 1.5) minutes and 1.7 (SD 1.0) minutes for midazolam and diazepam respectively. The mean times for endoscopy were also similar, three quarters of the examinations being done in less than two minutes.

The endoscopists rated both drugs as being equally highly satisfactory, on average "excellent" in $55 \%$ and "good" in $27 \%$ of cases. In contrast, the patients generally gave significantly better ratings to midazolam (table). Both the Trieger test and critical flicker fusion showed significantly more impairment at one hour in patients given midazolam but the speed of recovery thereafter was quicker, so that at two hours the results were similar and almost back to pretreatment values. Midazolam induced significantly more amnesia than diazepam; this correlated with better patient acceptability.

Pain on injection and tenderness, redness, and induration at the injection site occurred in $4 \%$ and $17 \%$ of patients after midazolam and diazepam respectively (difference not significant).

\section{Comment}

Intravenous midazolam was at least as effective as intravenous diazepam in allowing quick yet safe endoscopy. Furthermore, the patients graded the sedation with midazolam more highly and the amnesia superior compared with diazepam, though the study was not designed to allow direct patient preference. Venous complications were substantially fewer after midazolam. There were no adverse reactions. The rapid recovery and safety features allowed us to use
Patients' assessment. (Figures are percentages)

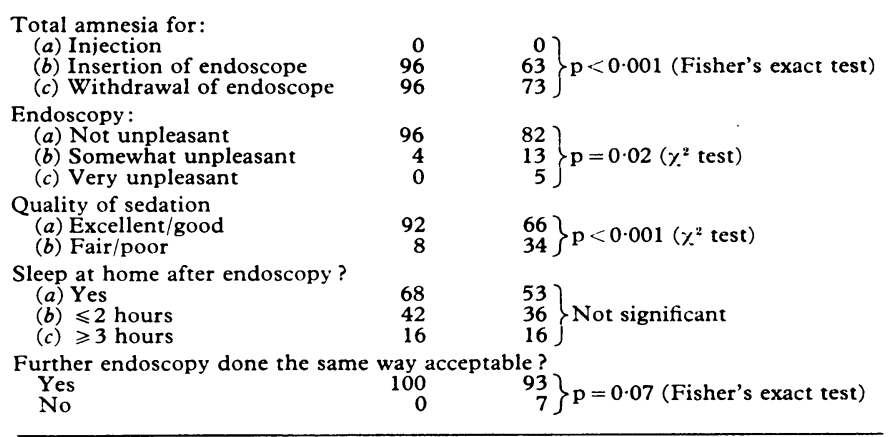

relatively larger doses of midazolam, ${ }^{3-5}$ which saved time with no increased risk. This may prove to be the drug of choice for endoscopy.

1 Newman MG, Trieger N, Miller JC. Measuring recovery from anaesthesia -a simple test. Anesth Analg (Cleve) 1969;48:136-40.

2 Parrott AC. Critical flicker fusion thresholds and their relationships to other measures of alertness. Pharmacopsychiatrica 1982;15:39-43.

${ }^{3}$ Al-Khudairi D, Whitwan JG, McCloy RF. Midazolam and diazepam for gastroscopy. Anaesthesia 1982;37:1002-6.

4 Whitwan JG, Al-Khudairi D, McCloy R. Comparison of midazolam and diazepam in doses of comparable potency during gastroscopy. $\mathrm{Br} \mathcal{F}$ Anaesth 1983;55:773-7.

${ }^{5}$ Magni VC, Frost RA, Leung JWC, Cotton PB. A randomised comparison of midazolam and diazepam for sedation in upper gastrointestinal endoscopy. Br $\mathcal{F}$ Anaesth 1983;55:1095-101.

(Accepted 13 fanuary 1984)

District General Hospital, Rotherham S60 2UD

K D BARDHAN, DPHIL, FRCP, consultant physician

PAMELA MORRIS, SRN, staff nurse

P C TAYLOR, MB, MRCP, medical registrar

R F C HINCHLIFFE, $\mathrm{MB}, \mathrm{CHB}$, general practitioner, clinical assistant

Roche Products Limited, Welwyn Garden City, Herts AL7 3AY

P A HARRIS, BSC, MB, head of medical affairs

Correspondence to: Dr K D Bardhan.

\section{Hypertension in pregnancy managed at home by community midwives}

In recent years the importance of providing antenatal care at home has been increasingly emphasised, ${ }^{1}$ and most clinicians have become increasingly reluctant to admit pregnant women to hospital except when absolutely necessary. Although there is good evidence that admission to hospital and bed rest do not improve the fetal prognosis in pregnant women with hypertension, ${ }^{2}$ many obstetricians have nevertheless continued with a policy of admission for uncomplicated hypertension in pregnancy to ensure close observation of the patient and to note any proteinuria. Midwives, however, can monitor patients closely at home and obtain more accurate readings of blood pressure (in some hypertensive states readings of systolic blood pressures noted in hospital tend to be about $10 \mathrm{~mm} \mathrm{Hg}$ higher than those noted at home ${ }^{3}$ ).

\section{Method and results}

In the Huddersfield health district in February to July 1982 hypertension in pregnancy with or without some other disorder accounted for $18.5 \%$ of all admissions to hospital after the 20th week of pregnancy. A prospective trial was undertaken to see whether admissions could be avoided by supervising hypertensive pregnant women at home. For six months from 1 February 1983 patients under my care who were more than 20 weeks pregnant and had hypertension were treated according to the following new policy.

Patients were not admitted to hospital from the antenatal clinic unless two separate readings taken at the clinic showed the diastolic blood pressure to be greater than $100 \mathrm{~mm} \mathrm{Hg}$. Any patient with a diastolic blood pressure 